\title{
ANALISIS PERBANDINGAN UNJUK KERJA PEMANAS AIR TENAGA SURYA TIPE PLAT DATAR DENGAN SISTEM SINGLE DAN DOUBLE CUTOFF
}

\author{
Ivan Budiman, I Made Kartika dan Abrar Riza \\ Program Studi Teknik Mesin, Fakultas Teknik Universitas Tarumanagara, Jakarta, 2016 \\ e-mail: Budimanivan15@gmail.com
}

\begin{abstract}
Warm water is needed by human being to take a bath, wash their clothes, their dishes etc. By the photothermal conversion, the solar energy can be used to heat the water. Flat solar collector is a tool which is used to capture energy of the sun radiation then convert it into heat to heat up water in collector's pipes. The number of glass cover used effects the performance and efficiency of the collector. From this research, it is found that the efficiency of the collector is better when the cover used are two glasses than one glasses. The temperature difference of incoming and outgoing water in the collector using two glasses $15^{\circ} \mathrm{C}$ higher than that of one glass.
\end{abstract}

Keywords: renewable energy, sun collector, photothermal conversion, water

\begin{abstract}
Abstrak: Air panas dibutuhkan manusia unutk berbagai keperluan seperti untuk mandi, mencuci baju, piring dan lain sebagainya. Dengan konversi fotothermal, maka energi panas matahari dapat dimanfaatkan untuk memanaskan air. Sebuah kolektor surya plat datar digunakan untuk memerangkap energi panas matahari dan panasnya diteruskan ke pipa-pipa yang berisi air sehingga terjadi peningkatan suhu dari air yang berada di dalam pipa tersebut. Jumlah kaca penutup dari kolektor mempengaruhi unjuk kerja dari kolektor. Secara umum diperoleh hasil bahwa dengan menggunakan dua buah kaca penutup diperoleh efisiensi yang lebih baik dibandingkan hanya menggunakan satu kaca. Perbedaan suhu antara air keluar kolektor dan yang masuk ke kolektor dengan dua kaca penutup bisa lebih tinggi hingga sekitar $15^{\circ} \mathrm{C}$ dibandingkan kolektor dengan satu kaca penutup.
\end{abstract}

Kata Kunci: energi tak habis pakai, kolektor panas matahari, konversi photothermal, pemanas air.

\section{PENDAHULUAN}

Pada zaman ini air panas dibutuhkan oleh masyarakat luas, misalnya untuk mandi ataupun mencuci barang yang berlemak akan lebih mudah melarutkannya dalam sabun dengan menggunakan air hangat dibandingkan dengan air dingin. Pada umumnya air panas diperoleh dengan cara memasak air dengan menggunakan bahan bakar. Perlu diketahui penggunaan bahan bakar, yang umumnya adalah bahan bakar fosil akan menimbulkan polusi udara, yaitu terbentuknya CO, NOx SO3 dan lain-lain. Selain itu bahan bakar jenis ini merupakan sumber energi yang tak dapat diperbarui sehingga suatu saat akan habis sehinggga perlu dicari sumber energi alternatif.

Untuk menghidari terbentuknya lebih banyak polutan, sejalan dengan penerapan ISO 9000 yang sejak tahun 1994 muncul dengan standarisasi di bidang lingkungan hidup, EMAS (EcoManagement and Audit Scheme) di Uni Eropa serta padanannya ISO 14000, maka salah satu solusinya adalah menggunaan peralatan penyerap energi matahari untuk memanaskan air. Indonesia yang terletak di daerah tropis ini sebenarnya memiliki suatu keuntungan cukup besar yaitu menerima sinar matahari yang berkesinambungan sepanjang tahun. Sayangnya energi tersebut kelihatannya dibiarkan terbuang percuma untuk keperluan alamiah saja. Tidak seperti halnya negara maju, yang giat meneliti pemanfaatan energi tersebut untuk kepentingan manusia, misalnya pemakaian sel fotovoltaik yang nantinya energi listrik yang diperoleh dapat digunakan untuk penggerak mobil, satelit, hubungan komunikasi ataupun disimpan di dalam sel-sel penyimpan.

Bagi negara berkembang, perlu diakui bahwa keterbatasan dana memang merupakan hambatan yang cukup penting. Untuk itu maka pemanfaatan energi matahari ini dapat dimulai dari yang sederhana yaitu menangkap energi yang berupa gelombang elektromagnetik itu dengan plat datar yang kemudian diteruskan ke pipa-pipa yang berisi air. Akibat thermosiphon circulation atau sirkulasi gravitasi maka air yang telah panas akan terdorong naik ke drum penyimpan dan tempatnya terisi oleh air yang masih relatif lebih dingin. 


\section{ALAT-ALAT PENELITIAN}

Pemanas Air Tenaga Surya

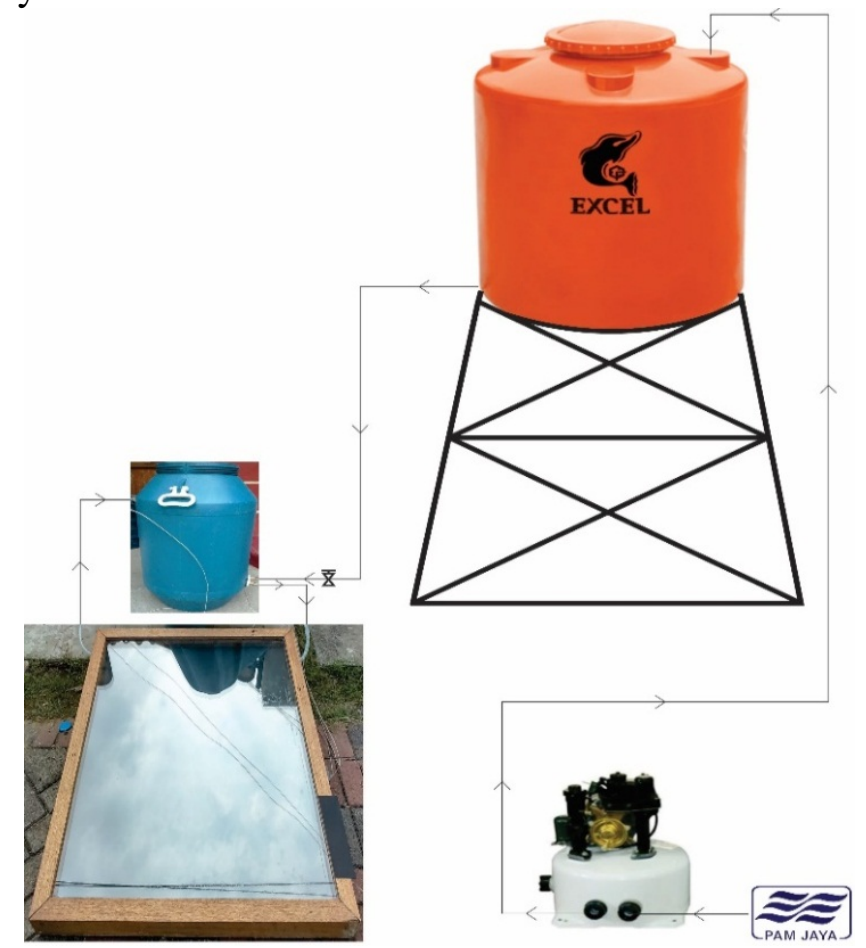

Gambar 1. Skema Pemanas Air Tenaga Surya

Pada sistem pemanas air tenaga surya ini dapat dibagi menjadi tiga unit fungsional, yaitu :

- Kolektor surya

- Reservoir air panas

- Pipa-pipa sirkulasi

Kolektor surya berfungsi untuk mengumpulkan radiasi matahari dan mengubahnya menjadi energi panas yang kemudian diteruskan ke fluida yang berada di dalam pipa-pipa kolektor. Pada kolektor surya ini diletakkan 22 buah pipa pada jarak yang sama, yaitu: $4 \mathrm{~cm}$, dimana pipa-pipa itu berhubungan dengan penyimpan air melalui selang. Plat penyerap radiasi matahari tersebut terbuat dari plat tembaga dengan ukuran 1,1m x 1m dan tebal 5mm. Sedangkan pipa-pipa tempat megalir air yang akan dipanaskan terbuat dari bahan tembaga dengan diameter 0,5 inch dan panjangnya masing-masing $90 \mathrm{~cm}$ x $90 \mathrm{~cm}$. Jarak antar pipa $40 \mathrm{~mm}$.

Penghubung antara pemanas air tenaga surya dengan torrent (penampungan air) menggunakan selang berserat yang tahan terhadap air panas dengan diameter 0,5 inch. Sebagai kaca penutup (cutoff) dipilih jenis kaca plat polos dengan tebal $5 \mathrm{~mm}$. Untuk mencegah kerugian aliran panas di dalam kolektor maka digunakan insulator dengan panjang 1,1m, lebar 1m, dan tebal 1,5 $\mathrm{cm}$.

\section{Thermometer Suhu}

Digunakan untuk mengukur suhu udara sekitar kolektor (suhu ambient).

\section{Thermocouple}

Merupakan alat yang digunakan untuk mengukur temperatur air pada torrent bagian atas (output) sebagai air keluar dari kolektor ke torrent dan bawah (input) sebagai air masuk ke kolektor dari torrent, serta pada empat titik yang berbeda pada kolektor. Jenis yang digunakan adalah tipe K yang berkemampuan mengukur suhu dari $0-400^{\circ} \mathrm{C}$. 


\section{Thermocontrol}

Merupakan pasangan dari thermocouple yang berfungsi untuk mengkonversikan tegangan yang dihasilkan thermocouple setelah dipanaskan hingga suhu tertentu menjadi angka, sehingga terlihatlah angka yang menunjukkan temperatur hasil pengukuran. Merek yang digunakan adalah FORT FT-C400 yang mampu membaca suhu dari $0-400^{\circ} \mathrm{C}$.

\section{Thermometer Suhu Tembak}

Alat ini digunakan untuk mengukur suhu pada benda dengan jarak tertentu. Dilengkapi dengan inframerah maka dapat dilihat titik mana yang diukur dengan menggunakan alat ini. Merek alat yang digunakan adalah tipe DT-8500H yang dapat mengukur suhu dari $0-550^{\circ} \mathrm{C}$.

\section{TEORI DASAR}

Energi panas yang dipancarkan oleh matahari dapat dimanfaatkan untuk memanaskan air dengan bantuan sebuah kolektor pemanas. Dengan didasari oleh teori efek rumah kaca (greenhouse effect), maka efektifitas pengumpulan panas dapat ditingkatkan. Sedangkan untuk memanaskan air dalam tangki penyimpanan (torrent) dapat memanfaatkan efek termosiphon.

Prinsip dasar untuk menghitung efisiensi kolektor ini adalah dengan membandingkan besar kenaikan temperatur fluida yang mengalir dalam kolektor dengan intensitas cahaya matahari yang diterima kolektor. Laju perpindahan panas konduksi dapat dinyatakan dengan:

Dimana

$$
q=-K A\left(\frac{d T}{d x}\right)
$$

$$
\begin{array}{lll}
q & : & \text { Laju perpindahan panas (watt) } \\
K & : & \text { Konduktifitas Termal (W/m.K) } \\
A & : & \text { Luas Penampang yang terletak pada aliran panas }\left(\mathrm{m}^{2}\right) \\
d T / d x & : & \text { Gradien Temperatur dalam arah aliran panas }(-\mathrm{k} / \mathrm{m})
\end{array}
$$

Laju perpindahan panas dapat dinyatakan dengan hukum persamaan pendinginan:

Dimana

$$
q=h A(T w-T)
$$

$$
\begin{array}{lll}
h & : \text { Koefisien konveksi }\left(\mathrm{w} / \mathrm{m}^{2} . \mathrm{K}\right) \\
A & : & \text { Luas permukaan kolektor surya } \\
T w & \left(\mathrm{~m}^{2}\right) \\
T & : & \text { Temperatur dinding }(\mathrm{K}) \\
q & : & \text { Laju perpindahan panas (watt) }
\end{array}
$$

Kapasitas kalor diartikan sebagai banyaknya kalor yang diserap oleh suatu benda bermassa tertentu untuk menaikkan suhu sebesar $1^{0} \mathrm{C}$. Satuan kapasitas kalor dalam sistem Internasional yaitu $\mathrm{J} / \mathrm{K}$. Untuk mengetahui banyaknya kalor yang dilepas atau diterima oleh suatu zat digunakan persamaan:

$$
Q=m \cdot C_{P} \cdot d T
$$

\section{Dimana}

$$
\begin{array}{llll}
Q & : & \text { Kalor } & \text { (Joule) } \\
m & : & \text { massa } & (\mathrm{Kg}) \\
C p & : & \text { Kalor spesifik } & (\mathrm{J} / \mathrm{kg} . \mathrm{K}) \\
d T & : & \text { Perbedaan suhu } & (\mathrm{K})
\end{array}
$$




\section{PROSEDUR PENGUJIAN}

Pengujian dilakukan di halaman depan rumah mulai tanggal 1 Juni 2016 sampai dengan 5 Juni 2016. Separuh waktu yang pertama digunakan untuk melakukan pengujian dengan kolektor yang hanya menggunakan satu kaca penutup dan pada paruh waktu yang kedua digunakan untuk melakukan percobaan dengan dua buah kaca penutup.

Adapun procedur percobaan, baik dengan penutup satu ataupun dua buah kaca penutup adalah sebagai berikut :

- Pemanas air tenaga surya diletakan dengan kemiringan 15 derajat terhadap bidang horizontal dan menghadap ke Tenggara.

- Waktu pengukuran dimulai pukul 09.00 hingga 15.00 WIB

- Selang waktu pengukuran 60 menit.

- Untuk mengetahui kenaikan suhu pada alat pemanas air, maka ditempatkan thermocouple di beberapa titik pada alat pemanas air.

- Percobaan dilakukan selama 5 hari, hari pertama dilakukan percobaan alat guna untuk memperbaiki sistem dari alat jika ada yang tidak berjalan dengan sempurna (trial \& error). Dua hari setelahnya dilakukan percobaan untuk satu kaca penutup dan dua hari terakhir dilakukan percobaan untuk dua kaca penutup.

\section{HASIL PERCOBAAN DAN ANALISIS}

Pada tanggal 1 Juni dilakukan percobaan dengan menggunakan satu kaca penutup guna untuk mengetahui kekurangan dan kegagalan pada sistem (trial \& error). Setelah semua sistem telah berjalan sesuai dengan seharusnya, pada tanggal 2 Juni hingga 3 Juni, dilakukan percobaan menggunakan satu kaca penutup, kemudian pada tanggal 4 Juni hingga 5 Juni dilakukan percobaan dengan dua kaca penutup kolektor. Dengan demikian data yang bertuliskan tanggal 2 hingga 3 Juni merupakan data kolektor dengan menggunakan satu kaca penutup dan yang bertuliskan 4 hingga 5 Juni merupakan data kolektor dengan menggunakan dua kaca.

Pada umumnya, pada saat awal mula, suhu air lebih rendah dari pada suhu udara di sekelilingnya. Kemudian setelah matahari bersinar maka suhu air akan meningkat perlahan-lahan. Data yang diambil mulai dari jam 09.00 WIB sebagai data awal acuan.

Penggunaan kaca pada kolektor surya sangat berpengaruh dalam peningkatan suhu dari suhu udara sekitar. Pada percobaan tanggal 3 Juni 2016 dengan menggunakan satu kaca penutup terlihat bahwa perbedaan peningkatan suhu pada ruang kaca dengan suhu udara sekitar (ambient) mencapai $4,1^{\circ} \mathrm{C}$ pada pukul $09.00 \mathrm{WIB}$ kemudian terus meningkat hingga mencapai $31^{\circ} \mathrm{C}$ pada pukul 13.00 WIB dan turun hingga mencapai $10,2^{\circ} \mathrm{C}$ pada pukul 15.00 WIB. Penggunaan dua kaca penutup mendapatkan kenaikan suhu lebih tinggi dibandingkan dengan satu kaca penutup. Pada percobaan tanggal 4 Juni 2016 terlihat perbedaan suhu yang cukup tinggi mencapai $9,2^{\circ} \mathrm{C}$ pada pukul 09.00 WIB kemudian terus meningkat hingga mencapai $36,3^{\circ} \mathrm{C}$ pada pukul $14.00 \mathrm{WIB}$ dan akhirnya turun hingga mencapai $28,6^{\circ} \mathrm{C}$ pada pukul $15.00 \mathrm{WIB}$.

Perbedaan penggunaan kaca penutup tersebut mempengaruhi suhu air yang keluar dari kolektor pemanas air. Untuk melihat perbedaan ujuk kerja dari kedua jenis kolektor ini maka dapat dilihat pada tanggal 3 Juni 2016 (satu kaca) dan 4 Juni 2016 (dua kaca) yang menampilkan perbedaan suhu air keluar dari kolektor. Perbedaan selisih temperatur dari penggunaan satu kaca dan dua kaca pada pukul 10.00 WIB masih sekitar $5^{\circ} \mathrm{C}$ saja kemudian naik menjadi $10^{\circ} \mathrm{C}$ pada pukul 11.00 WIB dengan selang waktu pengambilan data selama 60 menit dan terus naik hingga perbedaan suhu mencapai $13^{\circ} \mathrm{C}$ pada pukul 12.00 WIB. Sesudah itu perbedaan suhu antar dua kolektor turus menurun dari $11,9^{\circ} \mathrm{C}$ pada pukul $13.00 \mathrm{WIB}$, kemudian kembali lagi menjadi $5^{\circ} \mathrm{C}$ pada pukul $14.00 \mathrm{WIB}$ sampai akhirnya hanya berbeda $3,5^{\circ} \mathrm{C}$ pada pukul $15.00 \mathrm{WIB}$. 


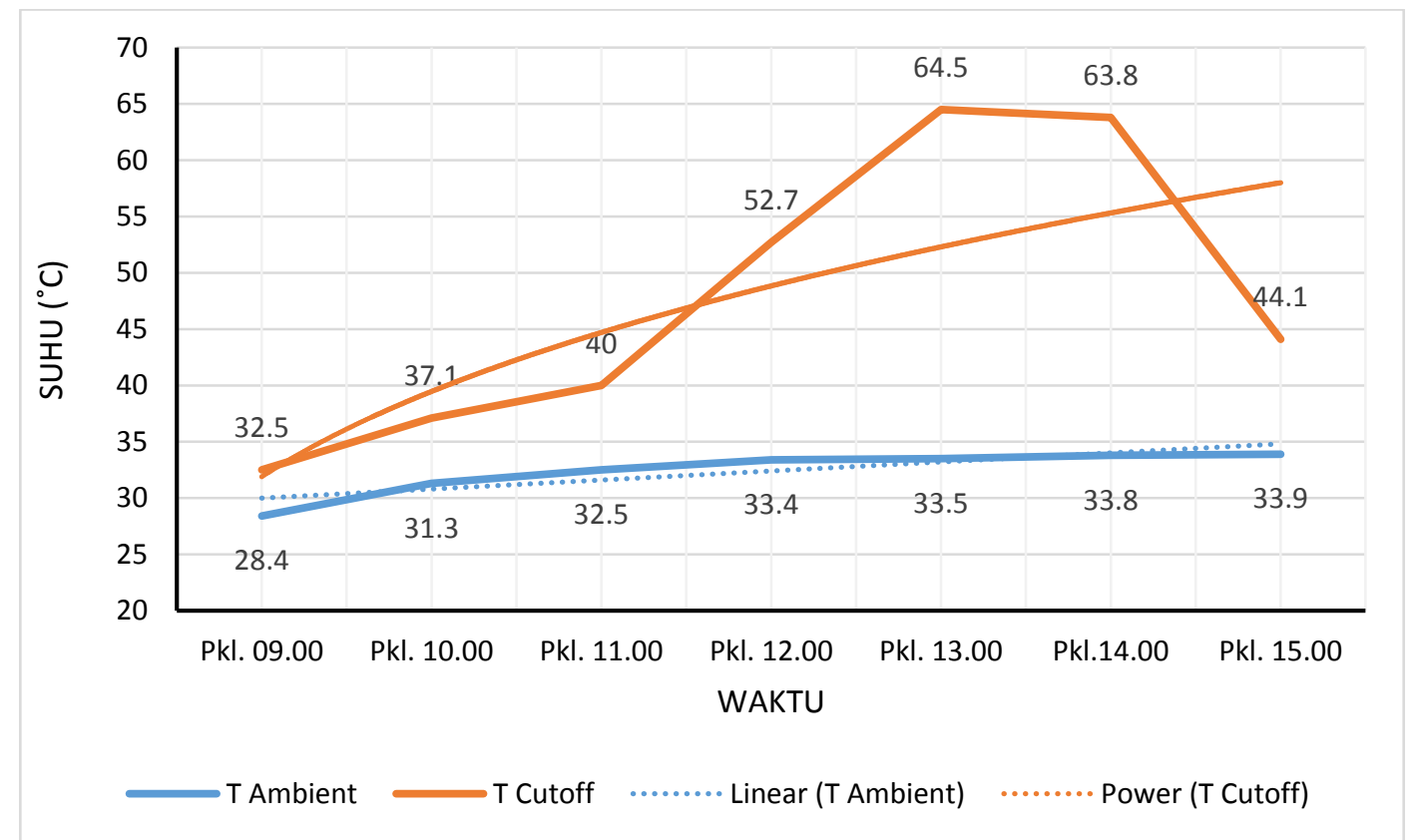

Gambar 2. Perbandingan suhu ambient dengan cutoff Jumat, 3 Juni 2016

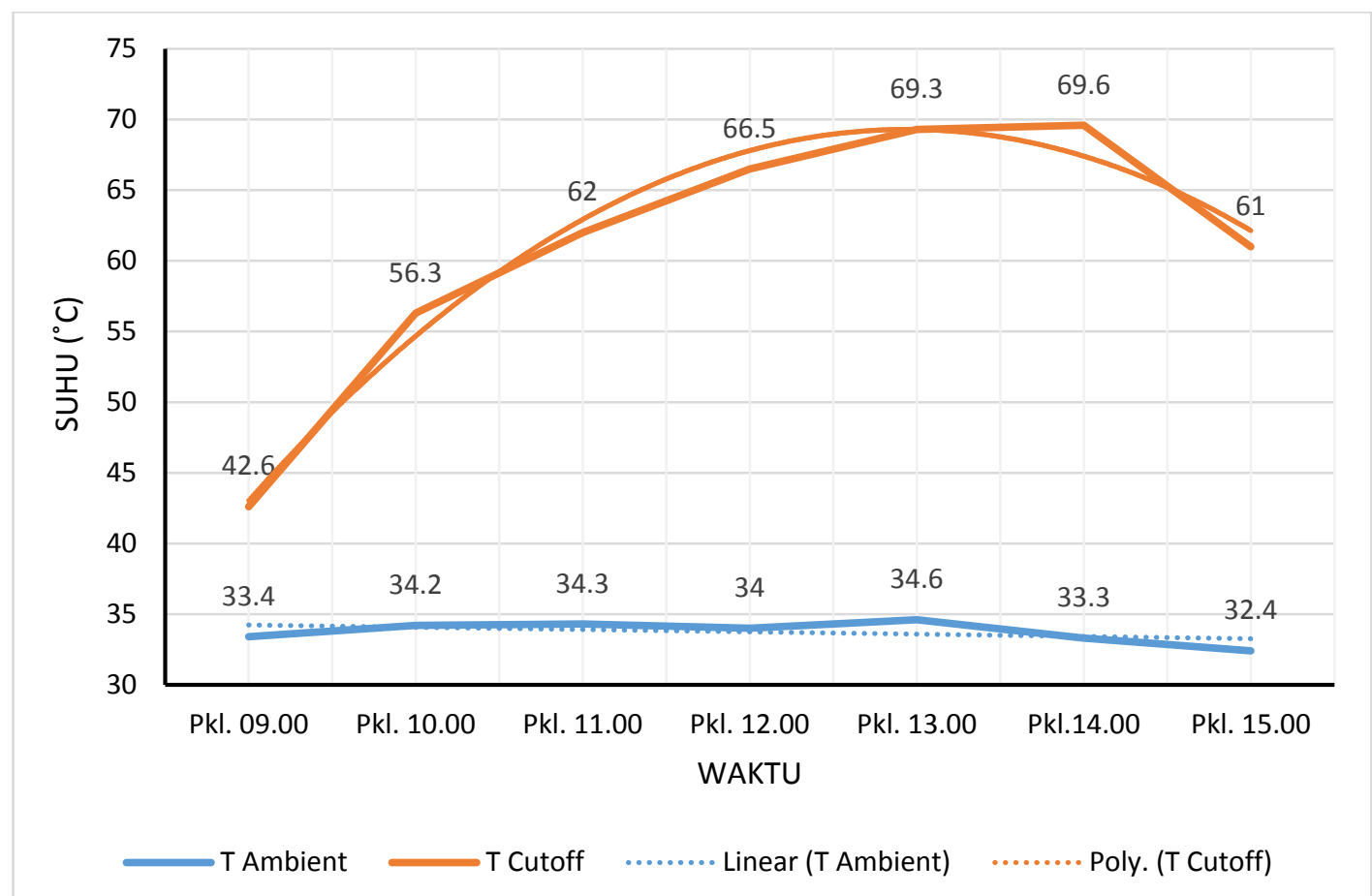

Gambar 3. Perbandingan suhu ambient dengan cutoff Sabtu, 4 Juni 2016

Yang cukup menarik dari hasil percobaan ini adalah suhu air keluar kolektor yang menggunakan dengan dua buah kaca penutup cepat meningkat dan mengungguli suhu keluar dari kolektor dengan sebuah kaca penutup. Tetapi suhu keluar ini kemudian mengecil mulai dari jam 14.00 WIB seiring dengan mulai menurunnya cahaya matahari.

Perbandingan kenaikan suhu air torrent terlihat tidak jauh berbeda, paling tinggi untuk kolektor dengan satu kaca penutup terjadi pada hari kamis, 2 Juni 2016 pada pukul 12.00 WIB yaitu $20.9^{\circ} \mathrm{C}$ dan untuk dua kaca penutup hanya berselisih $1,3^{\circ} \mathrm{C}$, terjadi pada hari Jumat, 3 Juni 2016 pada pukul $13.00 \mathrm{WIB}$ yaitu : $22,2^{\circ} \mathrm{C}$. 


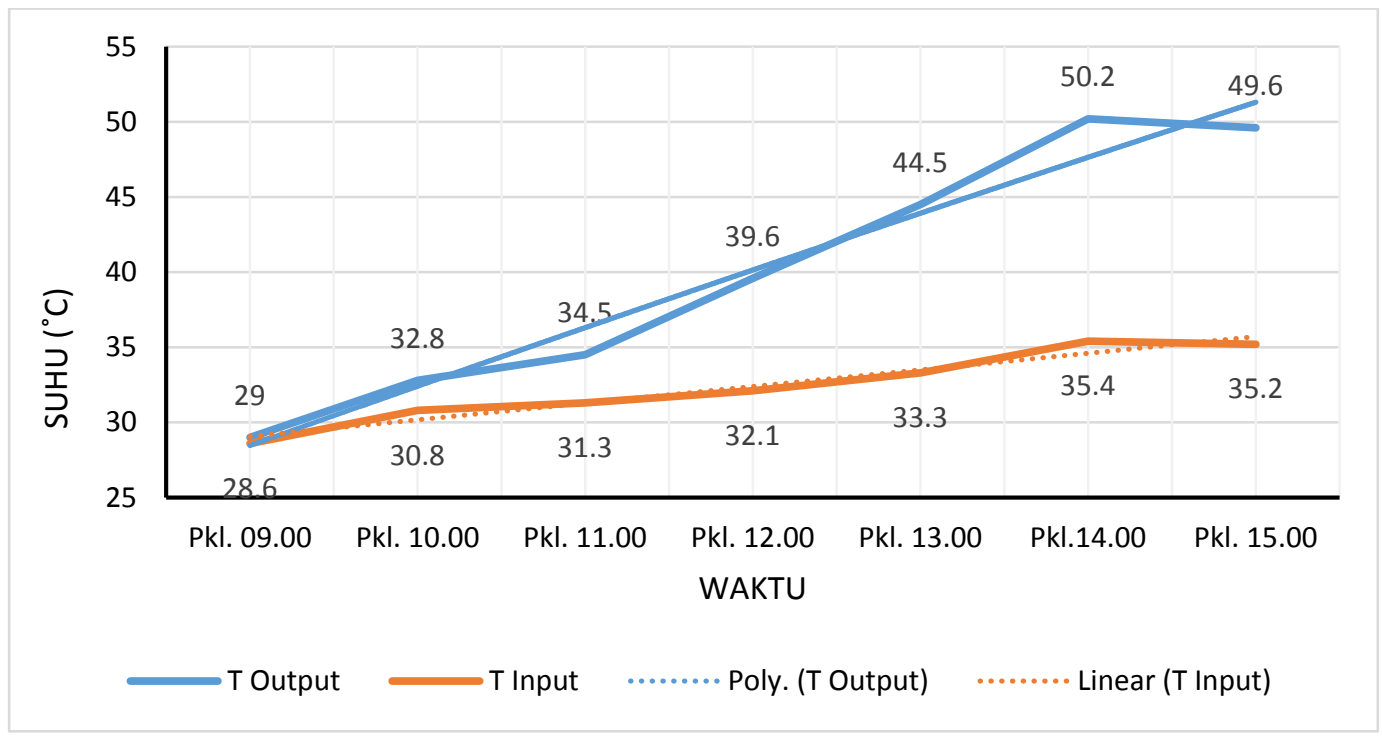

Gambar 4. Perbandingan suhu input dengan output Jumat, 3 Juni 2016

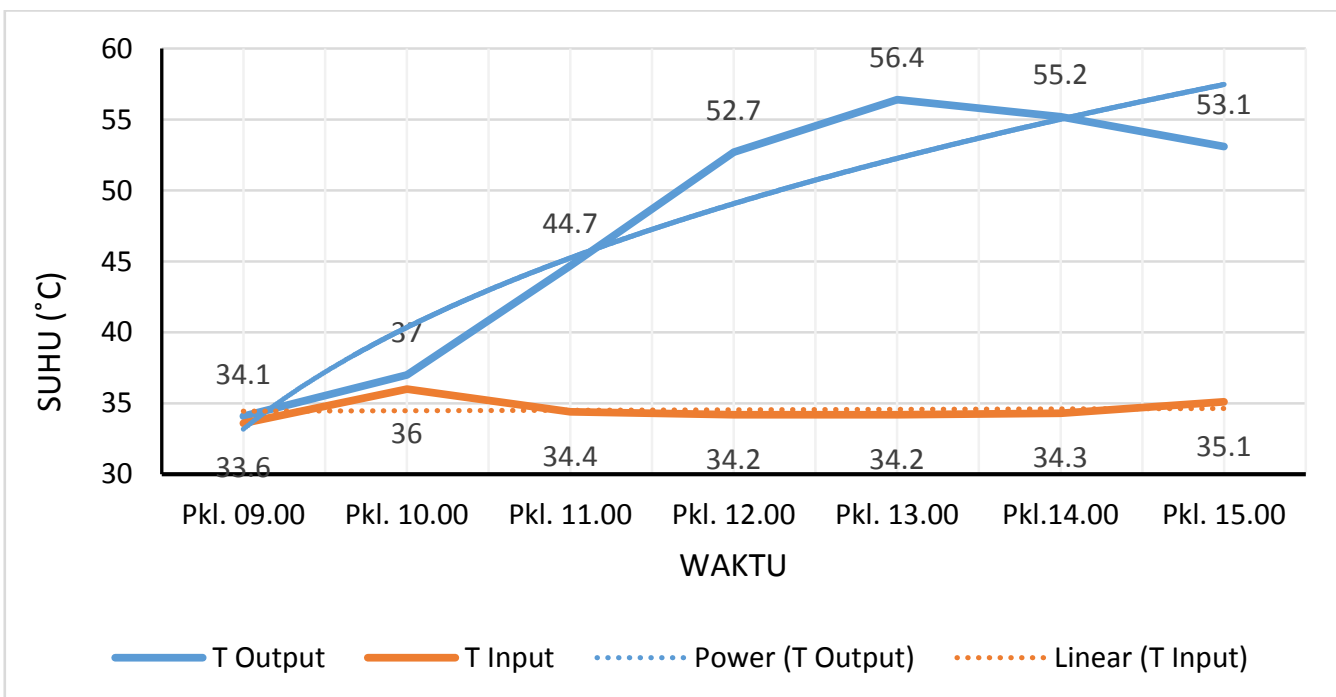

Gambar 5. Perbandingan suhu input dengan output Sabtu, 4 Juni 2016

Berikut adalah data hasil uji coba alat :

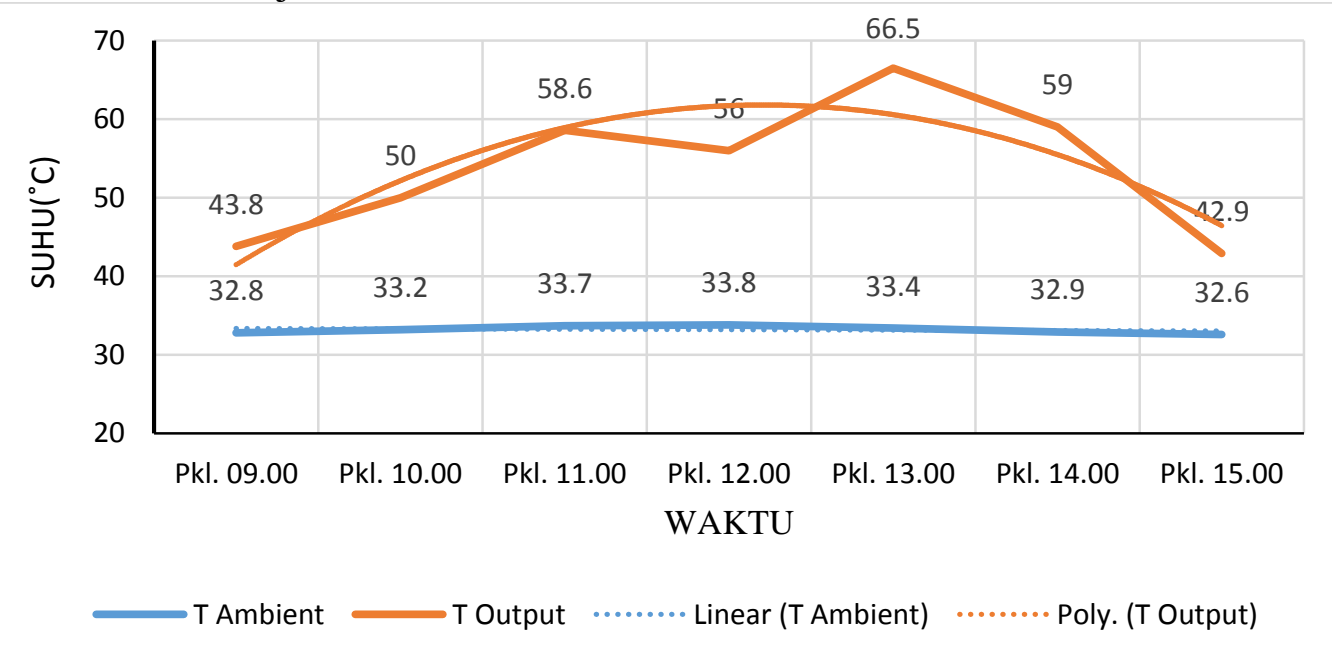

Gambar 6. Perbandingan suhu ambient dengan cutoff Kamis, 2 Juni 2016 


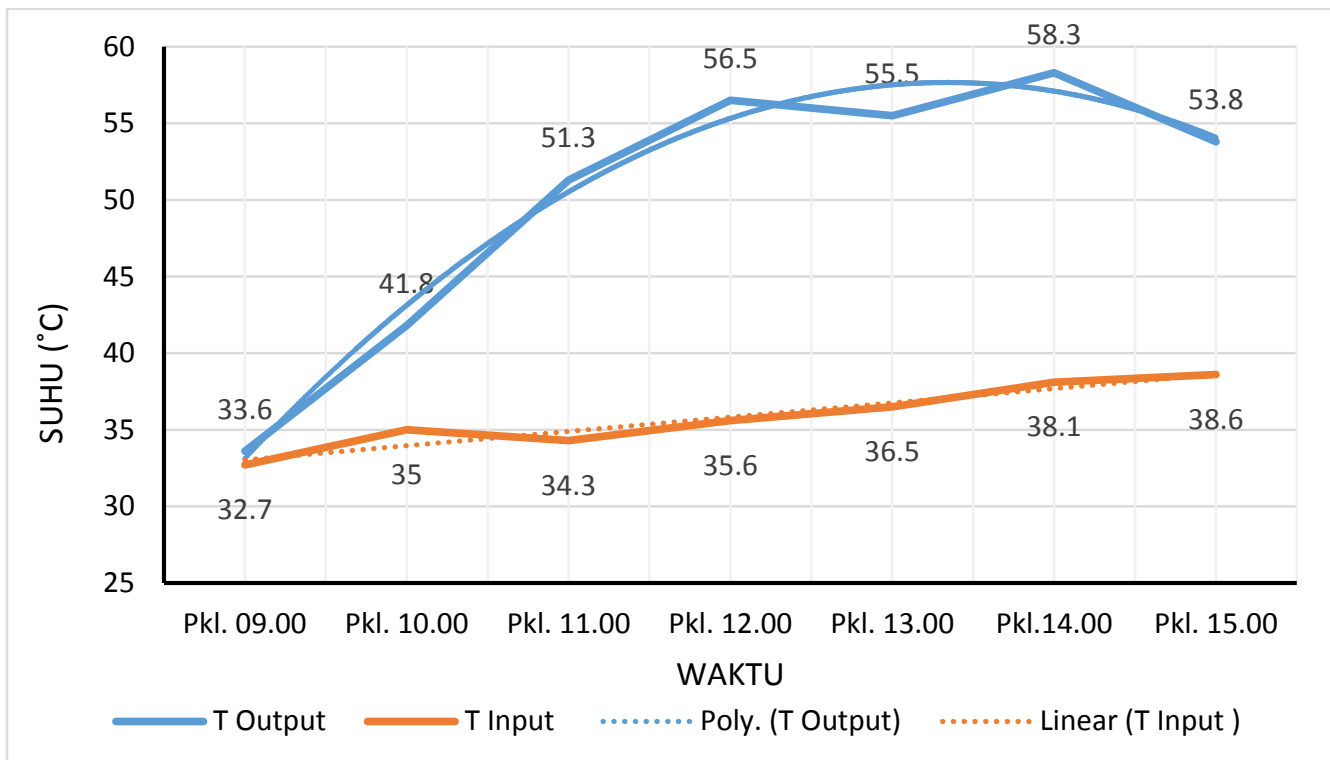

Gambar 7. Perbandingan suhu input dengan output Kamis, 2 Juni 2016

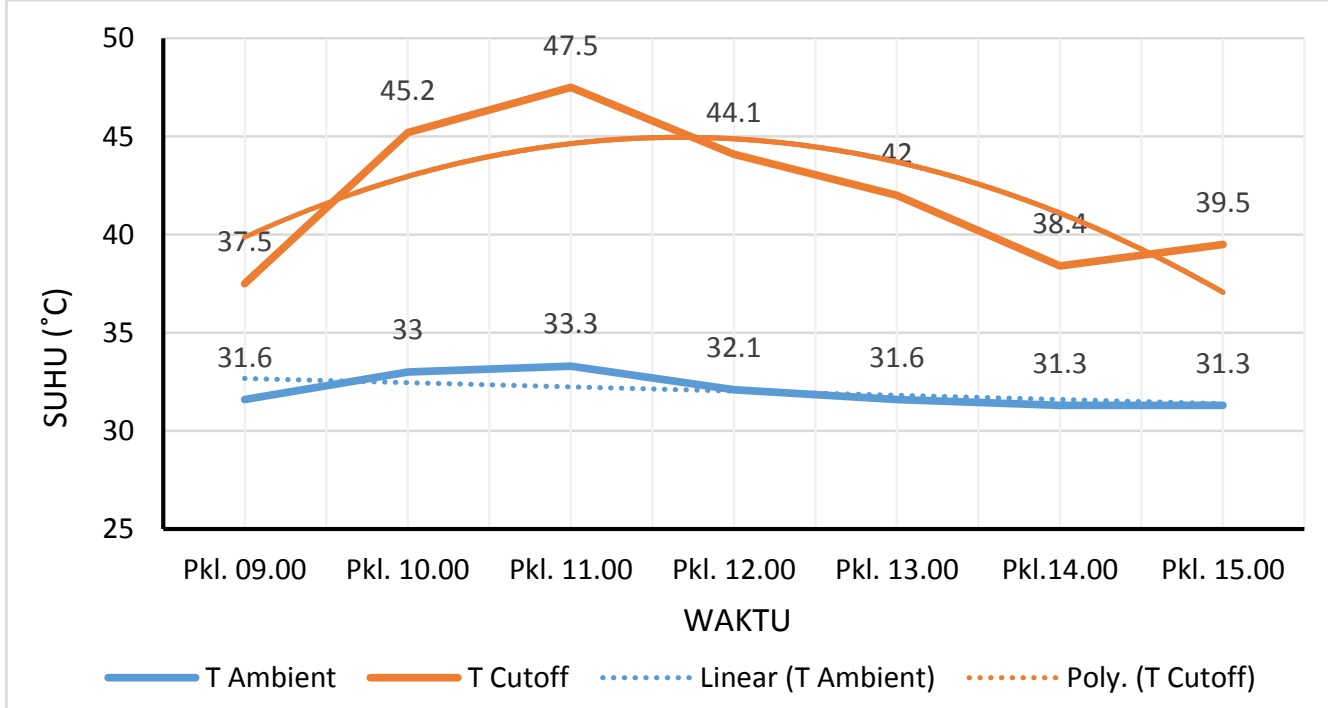

Gambar 8. Perbandingan suhu ambient dengan cutoff Minggu, 5 Juni 2016

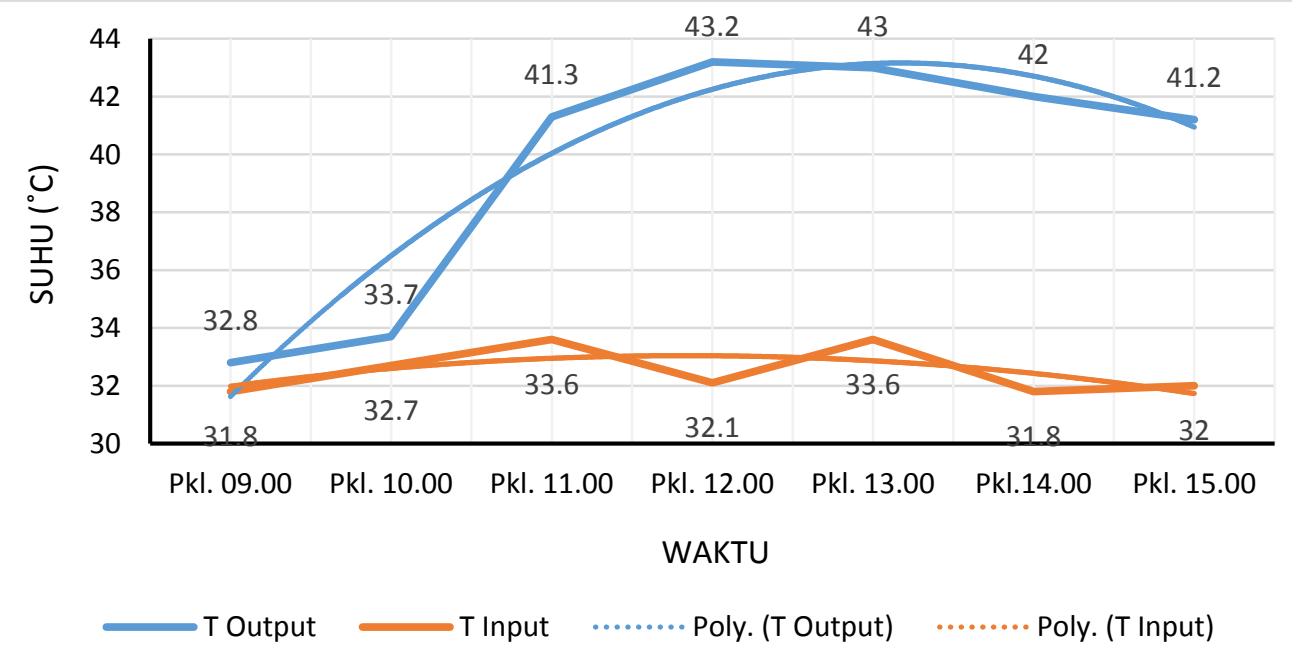

Gambar 9. Perbandingan suhu input dengan output Minggu, 5 Juni 2016. 
Kolektor dengan menggunakan dua kaca penutup menghasilkan suhu keluaran dan suhu antar kaca yang lebih tinggi dibandingkan dengan satu kaca penutup. Hal ini dapat dilihat pada grafik perbandingan suhu keluaran hasil uji coba hari Jumat dan Sabtu.

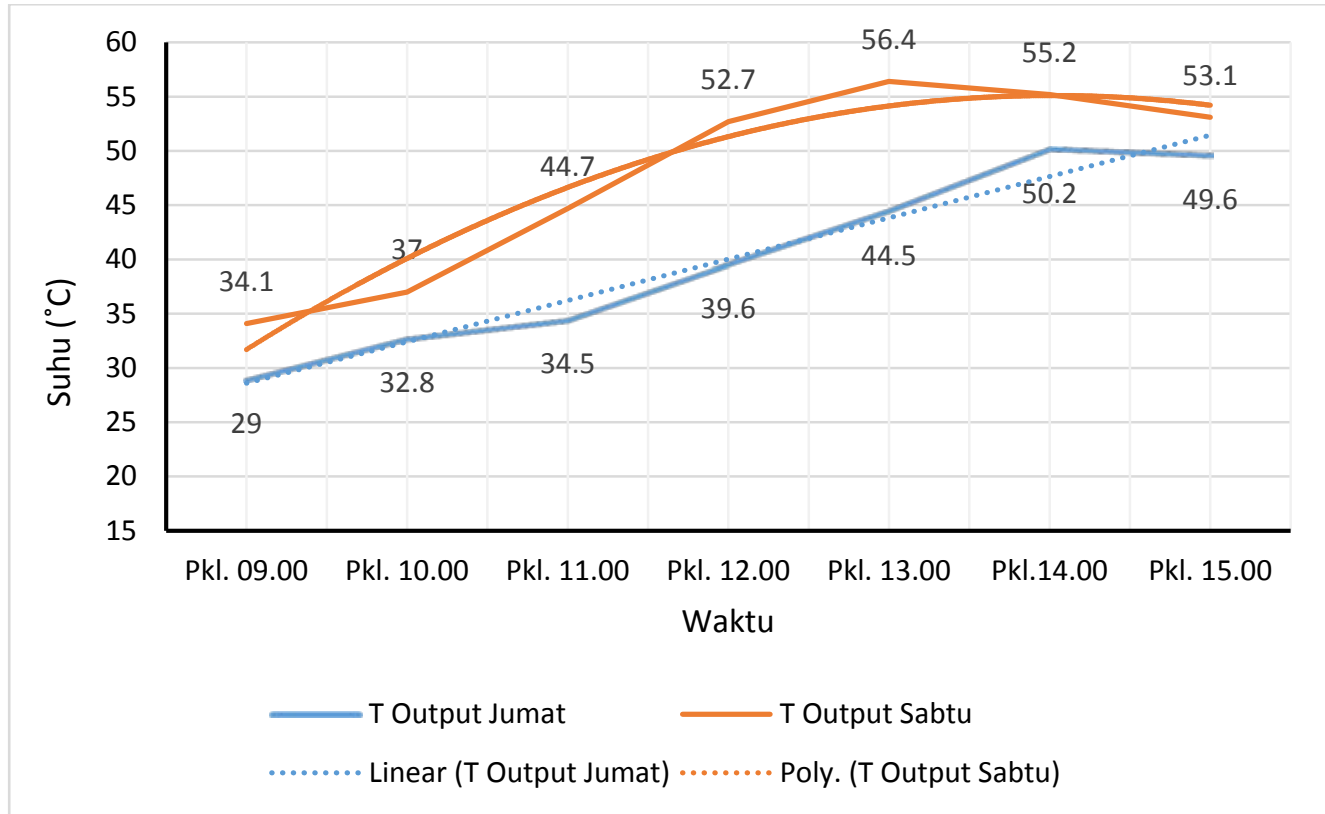

Gambar 10. Perbandingan suhu Output Jumat dan Sabtu

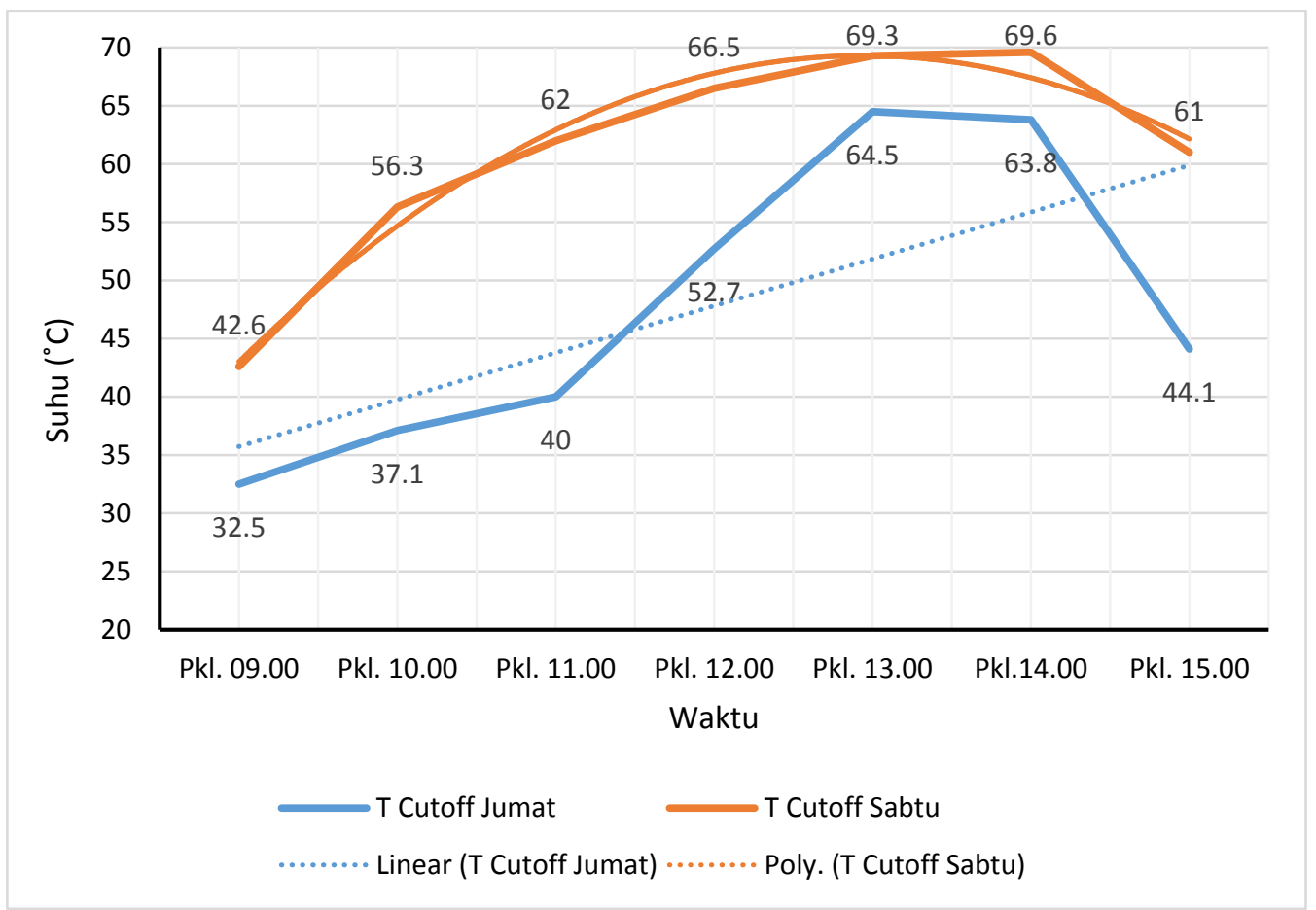

Gambar 11. Perbandingan suhu cutoff Jumat dan Sabtu

Percobaan yang dilakukan dalam penelitian ini, yaitu kolektor dengan satu kaca penutup dan kolektor dengan dua kaca penutup menunjukan hasil yang sesuai dengan teori dan hasil-hasil percobaan yang terdahulu. Dapat disimpulkan bahwa alat peraga kolektor surya yang dibuat dapat berfungsi dengan baik dan dapat digunakan untuk keperluan sehari-hari. 


\section{KESIMPULAN DAN SARAN}

Setelah melakukan percobaan, perhitungan dan analisis mengenai perbandingan pemanas air tenaga surya tipe plat datar dengan sistem single dan double cutoff dapat disimpulkan bahwa :

1. Pemanas air tenaga surya tipe plat datar berhasil dan dapat memanaskan air hingga mencapai suhu mendekati $60^{\circ} \mathrm{C}$. Dengan suhu maksimal mencapai $58,5^{\circ} \mathrm{C}$ sudah memenuhi suhu air panas rata-rata untuk mandi sehari-hari yaitu $45^{\circ} \mathrm{C}-50^{\circ} \mathrm{C}$.

2. Pemanas air tenaga surya plat datar yang dibuat menghasilkan kenaikan maksimum suhu air torrent hingga sebesar $22,2^{\circ} \mathrm{C}$, ini membuktikan bahwa penambahan kaca penutup berhasil meningkatkan kenaikan maksimum suhu air torrent.

3. Pemanasan yang paling baik terjadi mulai pukul 11.00 WIB - 13.00 WIB. Dengan hanya menggunakan sinar matahari langsung dan tidak menggunakan listrik untuk pengoperasian alat membuat alat ini hemat energi dan juga menghasilkan effisiensi sebesar 65\%.

Untuk kedepannya disarankan jika ingin melakukan pengujian atau membuat kolektor surya plat datar lebih baik menggunakan pompa air yang dapat mendorong air keluar dari kolektor menuju torrent. Perbanyak alat pengukuran untuk mengukur variabel-variabel yang dibutuhkan agar dapat dilakukan perhitungan secara mendetail.

\section{DAFTAR PUSTAKA}

[1]. Agung, Firdaus,. drr. (2009), Menyiasati Perubahan Iklim Di Wilayah Persisir Dan PulauPulau Kecil, Sarana Komunikasi Utama, Bogor.

[2]. Duffie, John and Beckman, William. 2006. Solar Engineering of Thermal Processes. New Jersey: Wiley

[3]. Holman, J.P. 1995. Perpindahan Kalor. Erlangga; Jakarta.

[4]. Lura, A. Eggers. 1979. Solar Energy in Developing Countries, Denmark : Pergamon Press.

[5]. Sidopekso, Satwiko. 2011. Studi Pemanfaatan Energi Matahari Sebagai Pemanas Air. Berkala Fisika 14 (1) 23-26.

[6]. Tim Contained Energy Indonesia. Buku Panduan Energi yang Terbarukan : PNPM Mandiri

[7]. Tirtoadmojo, Rahardjo. Jurnal Teknik Mesin Vol.1 No 2. Oktober 1999 : 115 - 121

[8]. Tripler. 1991. Fisika Dasar Jilid II. Erlangga. Jakarta: Erlangga. 